\title{
O Processo de Criação de Novos Negócios em Turismo: estudo de casos múltiplos em agências de viagens em Curitiba, Paraná
}

\author{
The Business Creation Process in Tourism: multiple case study in travel agencies in \\ Curitiba, Paraná
}

\section{El Proceso de Creación de Nuevos Negócios en Turismo: estudio de multiples casos en agencias de viajes en Curitiba, Paraná}

Rivanda Meira Teixeira ${ }^{1}$

\section{Resumo}

O objetivo deste estudo foi analisar o processo de criação de negócios, identificando os estágios de iniciação, preparação, start up e consolidação em quatro agências de viagens localizadas em Curitiba, Paraná. Foi adotado o modelo teórico de referência de quatro estágios de Borges, Simard e Filion (2005). O método de pesquisa utilizado foi o estudo de caso múltiplo, e as evidências foram coletadas através de entrevistas pessoais semiestruturadas com os empreendedores. Observou-se que os negócios iniciaram informalmente e que os empreendedores não possuíam informações sobre o setor. No estágio da preparação do negócio, constatou-se que, apesar do apoio gratuito oferecido pelo SEBRAE, os empresários iniciam seus empreendimentos sem realizar o plano de negócios. A consolidação do negócio foi o estágio mais difícil para todos os empreendedores, pois tiveram de lidar com problemas de sazonalidade e dificuldade de gerenciar o fluxo de caixa entre os períodos de alta e baixa estação. Além disso, os empreendedores apontam grande dificuldade em conciliar a vida pessoal e o negócio. No entanto, apesar das dificuldades enfrentadas, afirmaram que a atividade empresarial é compensadora, em função do retorno financeiro e da satisfação pessoal.

Palavras-Chave: empreendedorismo; turismo; processo empreendedor; criação de negócios; agências de viagens.

\begin{abstract}
The objective of this study was to analyze the business creation process identifying the stages of initiation, preparation, start up and consolidation in four travel agencies located in Curitiba, Paraná. Borges, Simard and Filion (2005) model of four periods was adopted as theoretical framework. The research method adopted was multiple case study and evidences

\footnotetext{
${ }^{1}$ Doutora em Administração pela Cranfield University na Inglaterra. Pós-Doutorado em Gestão Turismo na Bournemouth University, Inglaterra e Strathclyde University, Escócia. Pós-Doutorado em Empreendedorismo em Turismo na HEC Canadá. Professora do Mestrado em Economia (NUPEC) e Administração (PROPADM) da Universidade Federal de Sergipe. E-mail: rivandateixeira@terra.com.br.
} 
were collected through semi-structuralized personal interviews with entrepreneurs. It was observed that businesses were initiated informally and entrepreneurs do not have information about the sector. In the business preparation stage it was evidenced that, although the gratuitous support offered by SEBRAE, entrepreneurs initiated their enterprises without developing a business plan. The business consolidation was the most difficult stage for all the entrepreneurs because they had to deal with seasonality problems and difficulties to manage cash flow between high and low season. Moreover, the entrepreneurs point great difficulty in conciliating personal life and business. However, despite these problems, they affirmed that is compensating to be an entrepreneur, as a result of the financial return and personal satisfaction.

Keywords: entrepreneurship; tourism; entrepreneurial process; business creation; travel agencies.

\section{Resumen}

El objetivo de este estúdio fue analizar el proceso de creación de negócios, identificando las etapas de início, preparación, star-up y consolidación en cuatro agencias de viajes localizadas en la ciudad de Curitiba, Paraná. Fue usado el modelo teórico de referencia de las cuatro etapas de Borges, Simard y Filion (2005). El método de pesquisa utilizado fue el estúdio de casos multiples, y las evidencias fueron organizadas através de entrevistas personales semiestructuradas con los emprendedores. Se observó que los negócios comenzaron informalmente y que los emprendedores no tenian informaciones sobre el sector. En la etapa de preparación del negócio fue verificado que a pesar del apoyo gratuito ofrecido por el SEBRAE; los empresários comenzaron su empresa sin realizar un plano de negócios. La consolidación del negócio fue la etapa más difícil para todos los emprendedores pues tuvieron que enfrentar problemas de sazonalidad y dificultades para gerenciar el flujo de caja entre los periodos de alta y baja estación. Además de esa situación, los emprendedores indicaron una dificultad muy grande quando intentaron consolidar la vida personal con su negócio. Sin embargo, apesar de las dificultades enfrentadas, eles confirman que la actividad empresarial es compensadora teniendo en cuenta el resultado financiero y la satisfacción personal.

Palabras claves: empreendedorismo; turismo; proceso empreendedor; creación de negócios; agencias de viajes.

\section{Introdução}

Apesar da relevância econômica e social do turismo e do expressivo número de novos negócios que são iniciados a cada ano, poucos estudos no Brasil se voltam para o empreendedorismo nesse setor, que se apresenta, afirma Morrison (2004), como de grande potencial para a materialização de novos empreendimentos. Os empreendedores avaliam a 
viabilidade de entrada em um determinado setor econômico, comparando as oportunidades e baseando-se em uma série de critérios econômicos e sociais. O que parece especial a respeito da indústria do turismo, argumentam Lockyer e Morrison (1999), é que o setor tem forte apelo para os indivíduos que buscam uma combinação de atividades domésticas, de lazer e comerciais.

Os estudos sobre o empreendedorismo no Brasil têm ampliado sua relevância após a constatação da sua extensão e do seu significado para o desenvolvimento econômico e social do país. Segundo o relatório Global Entrepreneurship Monitor (GEM, 2010), o Brasil alcança a taxa de empreendedorismo em estágio inicial (TEA) mais alta nos últimos anos 17,5\%. Levando em conta uma população adulta no país em torno de 120 milhões de pessoas, esse valor representa 21,1 milhões de brasileiros empreendendo em 2010 (GEM, 2010).

Em função desse contexto, definiu-se como objetivo geral deste estudo analisar o processo de criação de negócios identificando os estágios de iniciação, preparação, start up e consolidação em quatro agências de viagens localizadas em Curitiba, Paraná. O modelo teórico de quatro estágios, adotado como referência, foi o de Borges, Simard e Filion (2005), que identifica os estágios e as atividades que ocorrem na criação de novos negócios. Esse modelo foi baseado em exaustiva revisão teórica sobre o tema e em um estudo empírico realizado no Canadá. Também foi destacado por Borges, Simard e Filion (2005) que a criação de negócios é um processo dinâmico e que os estágios e as atividades não ocorrem sempre na ordem indicada, podendo até se sobrepor.

\section{Contexto do Setor}

De acordo com o Instituto Paranaense de Desenvolvimento Econômico e Social- IPARDES (2008), as agências de turismo são o elo que ganha destaque na medida em que o turismo vem sedimentando-se como atividade econômica de relevância nos aglomerados urbanos. Se na década de 1990 exerciam um papel importante de captação de divisas, hoje a especialização e a diversificação das atividades fazem com que atuem focalizados em segmentos da demanda. Dessa forma, cumprem a função de dinamizar a atividade turística nas regiões do Estado onde atuam, como receptoras por excelência dos visitantes e turistas. Contudo, as agências de turismo possuem uma hierarquia de funcionamento que reforça o caráter assimétrico do 
mercado: o pequeno grupo de consolidadoras e operadoras controla a grande parcela das agências que realizam a atividade de emissivas, porque não possuem licença para operar no mercado em melhores condições (dadas as regulações sob as quais operam na emissão de passagens e pacotes aéreos e rodoviários, por causa de controles realizados pela EMBRATUR). A contratação de mão de obra local é grande entre as agências de turismo, sendo a atividade da cadeia que mais oferece treinamento. Mantêm um expressivo número de transações comerciais no Estado e também possuem considerável adesão às entidades e associações representativas do setor.

De acordo com dados do Instituto Paranaense de Desenvolvimento Econômico e SocialIPARDES (2008), os 636 estabelecimentos pesquisados no Estado representam 34,9\% dos 1.819 que declararam a Relação Anual de Informações Sociais (RAIS) em 2006 e contemplam 521 agências de turismo (varejistas) e 115 Operadoras, correspondendo, respectivamente, a $81,9 \%$ e $18,1 \%$ dos entrevistados. A maioria dessas empresas funciona, predominantemente, em imóveis alugados, localizados, em sua maioria, em estrutura comercial. A maior parte das empresas entrevistadas constitui a principal atividade dos proprietários, sendo geridas por eles próprios. Segundo o tempo de atividade, $44,3 \%$ das empresas iniciaram suas atividades após o ano 2000. Das agências de turismo pesquisadas no Estado, 84,6\% são empresas únicas, 4,9\% são filiais de cadeia nacional, e 3,5\% constituem matriz de cadeia nacional sediada no Paraná.

\section{Empreendedorismo em Turismo}

Entre os estudos que analisaram as características dos empreendedores do setor turístico, merecem destaque os clássicos de Glancey e Pettigrew (1997), o de Lynch (1998), o de Shivas (2001) e o de Lerner e Haber (2000). Dentre as principais características dos empreendedores dos hotéis pesquisados por Glancey e Pettigrew (1997), verificou-se que $64 \%$ deles tinham experiência anterior como gerentes ou supervisores e que a sua idade média era de 44 anos, o que pode refletir fatores particulares relevantes durante essa fase da vida, tais como experiência, educação e treinamento. Os empreendedores da amostra possuíam alto nível educacional, pois $64 \%$ tinham concluído a graduação. 
Em seu estudo com amostra de 43 mulheres empreendedoras do setor hoteleiro, Lynch (1998) encontrou uma realidade diferente do estudo de Glancey e Pettigrew (1997). A idade média dessas empreendedoras se situava entre 31 e 60 anos, a maioria era casada, com crianças e tinham parado de estudar na faixa de 19 anos de idade. Na pesquisa realizada em 53 empresas em Israel, por Lerner e Haber (2000), foi verificado que 87\% dos empreendedores eram do sexo masculino, que a idade média de 51\% situava-se entre $31-40$ anos, $25 \%$ entre 41-50 anos, 17\% entre 51-62 anos, e apenas 17\% tinham menos de trinta anos. Um terço dos respondentes tinha pais empresários e o nível educacional era alto: $62 \%$ tinham concluído o nível superior, $38 \%$ nível médio e quase metade dos respondentes estava tendo sua primeira experiência como empresário.

Shivas (2001), em survey realizada no Reino Unido, com uma amostra de 106 empreendedores do setor de hotelaria e de alimentação, encontrou que $77.4 \%$ dos entrevistados tinham mais de 45 anos e que o nível educacional desse grupo era alto, pois $69,8 \%$ tinham qualificação superior. No entanto, apenas $11 \%$ declararam ter tido algum tipo de qualificação formal voltada para turismo. Esse estudo destacou que um terço da amostra tinha tido experiência anterior como empresário.

Entre os estudos que destacaram as motivações dos empreendedores, um dos pioneiros foi o de Glancey e Pettigrew (1997). Os autores encontraram que as motivações para iniciar o negócio podiam ser divididas em dois grupos: a) fatores que empurram (push factors), como demissão, insegurança no trabalho, necessidade de complementar a renda; b) fatores que puxam (pull factors) foram "ser o próprio chefe", "conseguir lucros", "porque viu oportunidade de negócios", que são características dos empreendedores oportunistas. A maioria, $65 \%$ da amostra, mostrou possuir as características dos oportunistas.

Muitos pesquisadores identificaram a existência de motivações relacionadas ao estilo de vida (life styles motives) entre empreendedores do setor. Morrison, Rimmington e Williams (1999) destacam que os negócios no setor turístico são frequentemente iniciados por aqueles que buscam um estilo de vida no qual as necessidades da família, a renda e o modo de vida estejam equilibrados. Dewhurst e Herobin (1998) argumentam que existe a necessidade de avançar das definições puramente econômicas e propõem um modelo com um continuum entre os empreendedores com objetivos orientados para os aspectos comerciais e os 
orientados para o estilo de vida. Shaw e Williams (1998), por sua vez, discutem que empreendedores motivados para o estilo de vida geralmente não são orientados para os objetivos econômicos do negócio e aceitam manter negócios com lucros abaixo do desejado.

Outro estudo realizado por Getz e Peterson (2005), através de duas surveys conduzidas em empresa turísticas familiares no Canadá e na Dinamarca, testaram hipóteses relacionadas às motivações e estilo de vida (lifestyle); sobre os empreendedores voltados para autonomia (autonomy-oriented) versus empreendedores orientados para o crescimento e para o lucro. Os resultados mostraram que, nas duas amostras, a motivação dominante foi o estilo de vida (lifestyle). As motivações mais relevantes foram relacionadas à autonomia como "ser meu próprio chefe" e "me tornar financeiramente independente". O único estudo que abordou o processo empreendedor em turismo foi o de Haber e Reichel (2007), em uma amostra com 305 novas empresas do segmento turístico em Israel. Fundamentado na Visão Baseada em Recursos (RBV), esse estudo examinou empiricamente, no contexto da indústria do turismo, um modelo integrado combinando o processo empreendedor com a acumulação de recursos.

No Brasil, os estudos sobre o empreendedorismo em turismo são muito escassos e, de modo geral, enfocam temas como o comportamento e perfil do empreendedor, suas motivações para empreender e o desenvolvimento de competências empreendedoras. A seguir, alguns estudos recentes são destacados.

O estudo de Teixeira (2001) teve como objetivo efetuar uma avaliação através de uma análise comparativa entre os empreendedores das cidades de Belo Horizonte e Poços de Caldas (MG), a fim de identificar seus fatores de sucesso e fracasso. Os resultados da pesquisa revelaram que muitos dos empresários optaram pelo setor apenas por já atuarem como empregados ou por viajarem muito, demonstrando assim o despreparo e a falta de conhecimento para gerenciar o negócio, o que acarretou encerramento das atividades diante da dificuldade de gestão.

O desenvolvimento e a aprendizagem dos empreendedores em empresas de pequeno porte do setor hoteleiro foram analisados no estudo de Teixeira e Morrison (2004). Foi enfocado o processo de aprendizagem por meio da análise das competências; as percebidas como necessárias ao desempenho dos negócios, as necessidades de treinamento e de aprendizagem. Além disso, foi verificado também como as redes de relacionamento interferem nesse 
processo. Foram realizadas entrevistas com cerca de trinta proprietários de hotéis de pequeno porte. Os resultados reforçam as constatações observadas na literatura, relacionadas às dificuldades quanto às formas de aquisição e desenvolvimento das competências dos empreendedores, além de delimitar estímulos para o processo de aprendizagem contínua.

Sob a ótica do comportamento empreendedor, Barros e Moreira (2005) analisaram a organização produtiva de MPEs atuantes no segmento turístico da região de Canoa QuebradaCE. Os autores concluíram que, apesar das dificuldades e obstáculos enfrentados durante o início do processo de organização e a diversidade de interesses identificados, a região estudada destaca-se pela capacidade singular de se organizar e de se associar.

As competências empreendedoras dos proprietários de hotéis foram exploradas no estudo de Honna e Teixeira (2008), baseado em referencial teórico de Fleury e Fleury (2001) e Zarifian (2001) e no modelo de competências empreendedoras elaborado a partir de Man e Lau (2000) e Cooley. As principais conclusões deste trabalho mostram que não é possível afirmar que todos os empreendedores apresentem uniformidade em relação à caracterização de suas competências, em função da complexidade da análise e variação dos perfis profissionais e pessoais, experiências, histórias de vida, ambientes em que estão inseridos, características dos empreendimentos, diferentes ciclos de vida das empresas, mercados, estratégias e posicionamentos de mercado.

Feuerschütte e Godoi (2007) também analisaram as competências empreendedoras do setor hoteleiro a partir da reconstrução histórica de experiências de trabalho e da atuação dos sujeitos à frente do empreendimento. A estratégia da investigação qualitativa foi a história oral, mediada por entrevistas realizadas com empreendedores do setor hoteleiro. A identificação e a definição das competências construídas nas narrativas da história de vida demonstraram a vinculação entre os construtos competência do empreendedor e oportunidades empreendedoras, mediados pelo surgimento dos eventos críticos ou situações complexas enfrentadas pelos sujeitos. 


\section{Metodologia}

Este estudo pode ser classificado como exploratório, por investigar um campo em estágio teórico inicial, que é o empreendedorismo em turismo. Como afirmam Saunders, Lewis e Thornhill (2000), os estudos exploratórios buscam responder à pergunta: o que está acontecendo? O método de pesquisa utilizado é o estudo de caso múltiplo. Para Einsenhardt (1989), o estudo de caso é uma estratégia de pesquisa que se concentra no entendimento das dinâmicas presentes dentro de um único cenário. Yin (2005, p.73) afirma que, em estudos de casos múltiplos, uma questão a ser definida é o número de casos necessários ou suficientes para o estudo a ser realizado. Sua orientação é que, como não deve ser adotada uma lógica de amostragem, os critérios típicos adotados em relação ao tamanho da amostra também se tornam irrelevantes. Segundo Einsenhardt (1989), um número ideal para estudo de casos múltiplos ficaria entre quatro e dez casos. Abaixo disso, considera que seria difícil gerar uma teoria mais complexa ou ainda sua base empírica poderia não ser convincente. Este estudo analisou quatro casos de agências de viagens localizadas em Curitiba. Essas agências foram escolhidas porque foram fundadas e são gerenciadas pelos empreendedores que iniciaram esses negócios, para que sua experiência de todo o processo de criação do negócio fosse relatado.

As evidências foram coletadas através de entrevistas pessoais semiestruturadas com os empreendedores dessas empresas através de roteiro de entrevistas. As categorias analíticas adotadas neste estudo foram baseadas nas etapas e nas atividades do modelo processo de criação de negócios de Borges, Simard, Filion (2005, p.3): Etapa 1 - Iniciação, Etapa 2 Design e Preparação, Etapa 3 - Start-up, Etapa 4 - Consolidação. Além disso, foram definidas categorias analíticas para o perfil do empreendedor e as características do empreendimento.

\section{Análise dos Casos}

Para a realização da análise dos casos foram consideradas as categorias analíticas apresentadas na metodologia, quando se buscou identificar inicialmente as características do empreendimento e do empreendedor e as atividades que foram desenvolvidas ao longo das quatro etapas de criação do negócio: a iniciação, a preparação, o start -up e a consolidação. 


\subsection{Características das agências de viagens}

As agências de viagem analisadas neste estudo são de microporte, e apenas uma contratou um empregado. A gestão dos negócios é realizada pelos dois sócios em três agências; na agência 01, a condução do negócio é feita apenas pelo empreendedor, que teve um sócio quando iniciou o empreendimento, mas depois interrompeu a sociedade. São empresas recentemente criadas, só a agência 01 atua no mercado há cinco anos. A maioria dos clientes é turista de lazer. Duas agências também vendem seus serviços diretamente a empresas privadas para compra de passagem e reserva de hotéis. A agência 01 oferta maior variedade de serviços, enquanto a agência 03 é a única que oferece serviços diferenciados das demais, pois só vende intercâmbios no exterior.

\subsection{Características dos empreendedores}

Observa-se que a participação feminina e a masculina são iguais entre os empreendedores das agências de viagens de Curitiba: $50 \%$ dos entrevistados são do sexo masculino e $50 \%$, do sexo feminino. Os empreendedores são jovens, apenas um deles tem 44 anos: todos têm escolaridade superior. Esses dados corroboram os resultados de outros estudos (Barbosa e Teixeira, 1997, Teixeira, 2005 e Teixeira 2010) realizados com empreendedores do setor turístico que mostram que a maioria também era jovem e tinha formação superior. No entanto, a maioria dos empreendedores nesses estudos não tinha curso superior em turismo, o que não ocorreu com três dos entrevistados das agências de viagem analisadas. Vale destacar que todos buscaram qualificação adicional, realizando cursos relacionados à gestão de turismo. Nenhum dos empreendedores tinha familiares com negócios voltados para o setor turístico, sendo a escolha pela criação de negócio no setor decorrência de várias motivações.

Para o empreendedor da agência 01, a motivação de se tornar empresário surgiu enquanto trabalhava em um banco, e um grupo de amigos pediu que viajasse com eles para a Itália, pois era descendente de italianos, falava bem a língua e conhecia o país. Viu então uma oportunidade de negócios na organização de grupos para a Itália. Já a empreendedora da agência 02 viu a criação do negócio como uma possibilidade de ampliar sua renda e também se sentiu atraída pela flexibilidade de horário, pois podia continuar sua atividade docente, sua principal fonte de renda. Além disso, percebeu que era interessante aliar a teoria à prática, 
uma vez que lecionava agenciamento turístico. A empreendedora da agência 03 viu, na criação do próprio negócio, a única saída para seu crescimento como explica:

"Eu vi que, se eu continuasse trabalhando numa agência de viagens, eu não teria como crescer mais além daquilo. Eu já tava num cargo da área comercial e, além da minha função, seria o próprio proprietário. Então não tinha aquela perspectiva de crescimento dentro da empresa. Isso que me fez buscar meu próprio negócio".

Para o empreendedor da agência 04, a motivação principal foi aumentar a renda, já que o salário que recebia como empregado de hotel era muito baixo. Essas motivações encontram respaldo nos estudos de Morrison (2001), que, ao discutir sobre modelo de motivação que combinava as características e o ambiente pessoal do empreendedor, os seus objetivos e forças ambientais, concluiu que não era um evento simples ou uma característica específica que definia as motivações, mas uma combinação de vários elementos. Observou-se que dois dos empreendedores têm outras fontes de renda e apenas uma dos três empreendedores não se dedica integralmente à agência, pois, como é professora, enquanto leciona, deixa a sua sócia o cuidado do negócio.

\subsection{Estágio de iniciação}

As principais atividades desenvolvidas pelos quatro empreendedores durante o estágio de iniciação do negócio foram: identificação da oportunidade de negócio, reflexão e desenvolvimento da ideia do negócio e decisão de criar o negócio. O empreendedor da agência 01 planejou durante apenas seis meses antes de iniciar o seu negócio e contou com a experiência do ex-sócio, que era funcionário de companhia aérea e tinha experiência prática na venda de passagens aéreas. A ideia do negócio surgiu informalmente quando os amigos pediram que os levasse à Itália. Logo após levar o primeiro grupo, viu que existia potencial lucrativo na atividade. Resolveu criar uma agência de viagens porque consegue combinar o gosto de viajar, acredita ter paciência com as pessoas, além de não perceber perspectivas de crescimento pessoal na profissão de bancário.

Destaca como competências essenciais o conhecimento de línguas e dos sistemas aéreos, além de paciência. Para esse empreendedor, a principal dificuldade no estágio inicial do seu 
negócio foi a falta de informações sobre o setor, pois não existem dados publicados que possibilitem ao empreendedor inexperiente condições de conhecer o mercado em que vai atuar.

A empreendedora da agência de viagens 02 decidiu iniciar seu próprio negócio porque tinha experiência na atividade e, além disso, poderia conciliar sua atividade docente com o novo empreendimento e ter flexibilidade de horário. Considerou também que seria bom ter outra renda e, ao mesmo tempo, ter experiência prática para ensinar. Também não planejou seu negócio e teve a ideia enquanto trabalhava como funcionária em uma agência de viagens.

Considera que a sua ideia não foi original, mas tomou a decisão de não atuar com o público corporativo porque a concorrência era muito grande nesse segmento, como explica:

"Na verdade a gente só não queria trabalhar com público coorporativo. Essa é a ideia que a gente tinha. Se for pra trabalhar com publico coorporativo, melhor não. Porque tem gente que fica brigando por esse mercado. A gente sabe que tem agências que se matam pra conseguir esse público, mas não era nosso foco."

Destacou também a empreendedora da agência 02 a importância dos contatos para conseguir clientes nesta fase inicial:

\begin{abstract}
"No turismo tem que ter contatos. Tem que saber divulgar no momento certo, pra aquelas pessoas que você tem contato. Porque não adianta você ter uma relação de amigos imensa, só que ninguém sabe o que faz. Então acho que tem que ter no momento oportuno, mas aquelas pessoas que você tem um relacionamento saibam que você esta disposto a atender, e afinal, ganhar dinheiro com isso também".
\end{abstract}

Essa empreendedora destaca ainda a comunicação como competência básica para iniciar um negócio no setor, além de conhecimentos de informática e rotinas financeiras básicas como contas a pagar e receber.

A empreendedora da agência 03 iniciou o negócio aos poucos, sem muito planejamento; começou como free-lancer, sem escritório. Identificou a oportunidade de negócio porque 
sempre ia a feiras de intercâmbio e trocava ideias com as pessoas nesses eventos. Explica por que sua ideia de negócio foi original:

"Eu acho que tem um pouco de diferencial das outras, porque a gente é muito especializada em Austrália. Então, de Curitiba era só nós. A gente tem um contato muito bom, toda a parte de visto".

A maior dificuldade que a empresária da agência 03 enfrentou foi a resistência da família, pois, como não tinham negócios próprios, nem experiência empresarial, tinham receio de meu fracasso. Entre as competências que considera necessárias para iniciar o próprio negócio, destacou a experiência, a audácia e dinamismo. Por sua vez, o empreendedor da agência 04 relata o que fez no estágio inicial de criação de seu negócio. Comenta que a ideia do negócio surgiu durante o tempo em que trabalhou em hotel e também conversando com um amigo, que depois se tornou seu sócio. Planejou em apenas três meses, não conhecia o mercado e tinha poucas informações do setor. A decisão de atuar aí foi decorrente de considerar pequeno o investimento; além disso, a atividade lhe parecera fácil. Destaca que as competências técnicas mais relevantes para abrir um negócio desse tipo é informática, custos e sistemas de reserva e ter iniciativa. Considera que a maior dificuldade que teve nessa etapa foi consequência da sua falta de experiência como empreendedor e de lidar com a incerteza.

\subsection{Estágio de preparação}

Neste estágio, os empreendedores se voltam para a elaboração de plano de negócios, pesquisa de mercado, captação de recursos financeiros e definição da equipe. O empreendedor da agência 01 diz que ele mesmo fez um plano de negócios no qual levantou custos e receitas, mas, como enfatizou antes, não tinha informações do mercado e teve dificuldades porque os concorrentes não davam informações. Utilizou-se de capital próprio e decidiu comprar a sala onde iniciou suas atividades. Teve um sócio que tinha experiência na atividade, mas, após cinco anos, decidiu fazer concurso público e se afastou da sociedade.

A empreendedora da agência 02 não fez plano de negócios, e isso lhe parece não ter feito falta, pois já tinha experiência prática; preferiu ir aos poucos aprendendo com o negócio. Começou com uma sócia, que trabalhava na mesma agência e entrou com $50 \%$ do capital. 
Acha positivo ter sócio, porque pode dividir os custos e manter a sua atividade docente, enquanto a sócia atende os clientes. Não tem imóvel próprio.

Da mesma forma que na agência 01, a empreendedora da agência 03 fez seu próprio plano de negócio, mas contou com a ajuda do SEBRAE (Serviço Brasileiro de Apoio às Micro e Pequenas Empresas), cuja planilha usou como referência. Achou particularmente difícil fazer o planejamento financeiro porque não tem afinidade com a área, mas tinha boa noção do mercado e dos concorrentes. Inicialmente não teve sede própria e trabalhou no espaço de outra agência como free-lancer. Contou com recursos da família e do sócio, que entrou com $50 \%$ do capital inicial. Iniciou com um sócio que dá mais ênfase à parte financeira, o que foi muito bom para complementar as suas deficiências. Achou difícil nessa fase ter de fazer tudo e, ao mesmo tempo, montar o negócio.

$\mathrm{Na}$ agência 04, o processo de preparação foi informal. Fez um plano de negócios quando era estudante no trabalho de conclusão do curso, com dados muito estimados. Acha que a prática é diferente, existe muita imprevisibilidade: considera que, se fizesse um plano hoje, seria mais realista. Também começou o negócio com capital da família e mais 50\% do sócio, que era um colega de faculdade. Decidiu abrir em sociedade, uma vez que sentia mais segurança e podia dividir os riscos e os custos.

\subsection{Estágio de start-up}

Neste estágio são levados em consideração os procedimentos legais para a abertura do negócio, a organização das instalações e os equipamentos, o desenvolvimento dos serviços, a diferenciação dos competidores, as formas de competição, a contratação de empregados e os primeiros clientes. $\mathrm{Na}$ agência 01 , o empreendedor cuidou pessoalmente de todos os trâmites legais para a formalização do negócio e não sentiu dificuldade nesse processo, pois tinha a experiência do seu trabalho anterior como bancário. Assim que iniciou o negócio, decidiu dedicar-se integralmente à agência já que tinha saído do banco onde trabalhava e considerava que é difícil gerenciar um negócio desse tipo sem dedicação exclusiva porque, para ter sucesso, tem de fazer tudo.

A empreendedora 01 não teve dificuldade na compra do imóvel nem dos equipamentos de que precisou, pois são simples. Desenvolveu seus serviços informalmente: organizando viagens com amigos para a Itália aos poucos, porém, foi aperfeiçoando esse pacote. Sua situação pode 
ser considerada peculiar: primeiro, teve clientes e, depois, abriu a agência. Só teve dificuldades para aprender o sistema de bilhetes aéreos e tarifas, que acha complexo e detalhado.

A empreendedora na agência 02 contou com a ajuda de um contador para cuidar de todos os trâmites legais do negócio e disse que o processo foi rápido, sem problemas. Como já trabalhava como docente, não se dedica inteiramente ao negócio, mas a sua sócia, sim. Escolheu o local do escritório pela facilidade de acesso para os clientes e para as sócias. Começou usando móveis emprestados enquanto os do escritório eram manufaturados. A empreendedora destacou que não comprou sistemas de informática porque eram caros, que foi desenvolvendo suas próprias planilhas de contas a pagar e a receber.

A escolha dos hotéis fornecedores de serviços foi feita aos poucos, experimentando e também através da indicação de amigos e clientes. Antes de começar a agência formalmente, já tinha o primeiro cliente; o grande diferencial é a flexibilidade de horários: atende em qualquer dia e a qualquer hora procurando oferecer serviço personalizado e de qualidade, conforme explica:

"A gente pode atender ele fora do horário comercial: se for domingo de manhã, por exemplo, a gente vem e atende. Se quiser, por exemplo, terçafeira às nove horas da manhã, que é o horário que o cliente pode, a gente vai atender nesse horário".

$\mathrm{Na}$ agência 03, a empreendedora também contratou os serviços de contabilidade para a legalização do negócio, porém teve problemas com ele e teve de mudar de prestador; o processo da legalização trouxe-lhe muita preocupação. Comprou um sistema de controle financeiro muito bom, que ajuda muito a gestão do negócio e contratou um empregado desde o início. O primeiro cliente surgiu quando a agência ainda não existia: foi enquanto viajava pela Austrália. Depois continuou operando, mesmo sem ter a agência formalizada.

A agência 04 também usou os serviços de contador e achou o processo demorado e caro. Escolheu o local em função do valor do aluguel: procurou o mais barato. Como diferencial nos serviços, oferece turismo ferroviário e viagens com trilhas a pé. A maioria dos clientes veio inicialmente por indicação de amigos e parentes. A maior dificuldade para a gestão do 
negócio é ter um pro labore fixo, pois a renda da agência é muito variável; além disso, destaca que sente falta de maior conhecimento de gestão financeira.

\subsection{Consolidação}

Neste estágio, são consideradas as atividades de marketing/vendas, o ponto de equilíbrio, a administração do negócio, a incorporação de novas ferramentas de gestão, a conciliação da vida pessoal e do negócio e desafios futuros para a sobrevivência. Na agência 01, o marketing é feito através de mala direta via internet e no boca a boca dos clientes; o empreendedor considera que é muito fácil perder os clientes, por isso é preciso sempre estar em contato. Informou que conseguiu o ponto de equilíbrio logo no segundo mês, que cobria as despesas, mas não a amortização do valor do imóvel. Desde que iniciou o negócio, foi ficando mais cuidadoso com o gerenciamento da parte financeira. Acha muito complicado conciliar a vida pessoal e o negócio, pois tem de viajar muito, trabalhar sábado e domingo e muitas vezes ficar trabalhando até tarde. Considera que o maior desafio é a grande concorrência, o acesso que os clientes têm a informações sobre hotéis, tarifas, roteiros turísticos e, assim adquirem mais independência Outro problema é que o empreendedor do micronegócio é muito só, não tem apoio, nem existe treinamento específico para negócios turísticos. Avalia que o negócio não é muito lucrativo, dá muito trabalho, mas sente muita satisfação pessoal por ter seu próprio negócio.

As atividades de marketing da agência 02 também são limitadas e consistem apenas no envio de mensagens por correio eletrônico. A empreendedora disse que não demorou a atingir o ponto de equilíbrio, mas considera a sazonalidade do negócio o seu problema gerencial mais complicado, como explica com suas palavras:

"Como a gente trabalha com sazonalidade, tem assim um inconveniente. Sempre tem que ter um caixa, meio que guardadinho ali, porque se não vender nada durante um mês, a gente sabe que tem que cuidar. A gente até não pode se queixar porque, três meses depois, a gente já tava pagando as contas do mês".

Avalia essa empreendedora que lhe é difícil conciliar a vida pessoal com o negócio, pois, além da empresa, tem a atividade docente, família e filhos. Considera a concorrência no setor 
muito grande e desleal, pois proliferam de agências, e muitas trabalham sem ética. A fase de consolidação é avaliada como a mais difícil para a empreendedora, uma vez que, como explica, há muitos fatores que influenciam:

\begin{abstract}
"Consolidar o negócio é mais difícil. Porque quando a gente tá começando, você tá naquele gás. Então você tá gastando todo seu tempo em função de que aquilo tem que dar certo, tem motivação. Agora chega uma época que você só começa a ter noticia ruim. Então é a economia, é câmbio, aí a gente começa a se preocupar mais com isso".
\end{abstract}

No entanto, apesar das dificuldades, a empreendedora considera a atividade empresarial compensadora, como comenta:

\begin{abstract}
"Compensa. Tem a parte de valorização pessoal. A satisfação pessoal, acho que vale mais do que de repente você tá com uma fatura atrasada de companhia aérea. Mas se o cliente chegar e falar pra você olha: deu certo. É uma satisfação enorme, de você ter teu trabalho certinho do inicio ao fim. Apesar disso, você ta conhecendo pessoas novas, você tá aprendendo todos os dias. Claro que se a gente pagasse menos imposto e, além disso, tem toda essa parte burocrática”.
\end{abstract}

A agência 03 investiu mais em marketing que as demais. Além da indicação boca a boca, colocou anúncios em jornais, fez promoções via correio eletrônico e promovem alguns eventos. Ainda não chegou ao ponto de equilíbrio, pois o negócio é recente, apenas três anos de funcionamento. Também destaca o problema da sazonalidade, meses bons e meses fracos.

Tem dificuldade de separar a vida pessoal do negócio, pois trabalha fins de semana e à noite, vive para a empresa, não tem marido e filhos; pode se dedicar. Considera que esta etapa é a mais difícil, sobretudo pela gestão financeira do negócio e os altos impostos.

"Eu acho que essa parte financeira é a mais difícil, em função dos custos elevados e dos impostos altos. Manter o retorno rentável não é fácil. Trabalhar e trabalhar, e pagar mil impostos. E você tem que ter muita calma, tem que ter tranqüilidade. Certamente o retorno não é o desejado". 
A exemplo dos demais empreendedores, apesar de tudo, a empreendedora da agência 03 considera a atividade empresarial compensadora, como revela:

"Eu amo o que eu faço, amo esse lugar. Eu, quando tava trabalhando como funcionária em agência, eu questionava muito se eu deveria ter entrado na faculdade de turismo mesmo, se era isso que eu queria; eu sempre ficava na dúvida. Hoje me sinto bem realizada".

$\mathrm{Na}$ agência 04 , também a forma de propaganda é o envio de mensagens eletrônicas e o boca a boca dos clientes. O empreendedor considera seu maior problema é a compra direta pelo cliente que tem informações pela internet. Quem vai à agência é o pessoal mais velho, já acostumado a esse serviço. Ainda não alcançou o ponto de equilíbrio, pois tem apenas um ano de funcionamento e, no começo, o investimento foi alto. Nessa fase, considera que a maior dificuldade é organizar melhor o controle de custos e fazer a negociação com as operadoras.

O empreendedor da agência 04 tem dificuldade de conciliar a vida pessoal com o negócio, pois não consegue separar, guarda os problemas na cabeça, não consegue esquecer nem relaxar. Além disso, acha complicado manter a motivação para dirigir a empresa. De forma geral, o seu maior desafio é conseguir novos clientes e volume para manter o negócio. Se fosse iniciar agora, procuraria alugar uma sala mais barata, ter custos menores. Considera que não existe apoio aos empreendedores e que tem muitos impostos para pagar. No entanto tem esperança de que ainda vá melhorar, pois gosta do trabalho que faz.

\section{Conclusão}

O objetivo deste estudo foi analisar o processo de criação de negócios identificando os estágios de iniciação, preparação, start up e consolidação em quatro agências de viagens sediadas em Curitiba, Paraná. As empresas analisadas, recentemente criadas, são de microporte. São gerenciadas pelos seus proprietários, quase sempre com ajuda dos sócios. Os empreendedores são jovens, com menos de trinta anos; apenas um tem mais de quarenta anos. Todos possuem curso superior completo. Os empreendedores procuravam independência 
financeira e possibilidades de crescimento que não tinham em seus empregos antes de iniciar o negócio.

No estágio de iniciação, pode-se perceber que, de maneira geral, as ideias surgiram informalmente; também é percebível não terem os empreendedores informações prévias sobre o setor. Na preparação do negócio, constatou-se que, apesar do apoio gratuito oferecido pelo SEBRAE, os empresários iniciam seus empreendimentos sem realizar o plano de negócios ou pesquisa de mercado, ferramentas fundamentais para avaliar a viabilidade econômica de um empreendimento. Além disso, utilizam capital próprio ou da família.

O estágio start-up foi caracterizado pelas dificuldades de dois empreendedores na legalização do negócio. Observou-se que apenas uma empreendedora não se dedica integralmente à atividade e que não houve dificuldades para conseguir os primeiros clientes, pois em todos os casos os clientes já existiam ou foram conseguidos através de contatos pessoais.

A consolidação foi o estágio mais difícil para todos os empreendedores das agências de viagens, uma vez que tiveram de lidar com problemas de sazonalidade e gerenciar o fluxo de caixa entre os períodos de alta e baixa estação. Nesse estágio observaram-se também problemas no gerenciamento financeiro e, ademais, conciliar a vida pessoal e o negócio.

Os empreendedores enfatizaram, em todos os estágios, a necessidade de melhor preparação para criar e implementar negócios. Entretanto, apesar das dificuldades enfrentadas, afirmaram que a atividade empresarial é compensadora, em função do retorno financeiro e da satisfação que traz.

Diante das inúmeras dificuldades apontadas pelos entrevistados, sugere-se às agências de apoio aos pequenos negócios e ao setor público a busca de estratégias para facilitar a criação de novos negócios turísticos, dentre elas a ênfase na oferta de treinamento específico para o tipo de negócio, a disponibilidade de informações sobre o mercado e o incremento de parcerias no intuito de promover maior integração das atividades turísticas.

\section{Referências}

BARBOSA, J. D.; TEIXEIRA, R. M. Avaliação da Oferta Turística: Uma Contribuição dos Empresários para a Formulação de Estratégias Para o Setor. In: Encontro Nacional dos Programas de Pós-Graduação em Administração, 21, Rio de Janeiro. Anais.... Rio de Janeiro: ANPAD, 1997. 
BARROS, F. S. de O.; MOREIRA, M. V. C .O Comportamento Empreendedor e suas Implicações: A Organização Produtiva de Micro e Pequenas Empresas no Turismo. In: Encontro Nacional dos Programas de Pós-Graduação em Administração, 29, Brasília. Anais.... Rio de Janeiro: ANPAD, 2005.

BORGES C.; SIMARD G.; FILION L. J. Venture Creation Processes in Quebec Research Findings 2004-2005. Working Paper, 2005-07, HEC Montreal, May.

DEWHURST, P. and HOROBIN, H. Small business owner. In: THOMAS, R. (ed.). The Management of Small Tourism and Hospitality Firms. London, Cassell, p. 19-38, 1998.

EISENHARDT, K. M. Building theories from case study research. Academy of Management Review, v.14, n.4, p. 532-550, 1998

FEUERSCHÜTTE, S. G.; GODOI, C. K. Competências Empreendedoras: um Estudo Historiográfico no Setor Hoteleiro, in: Encontro Nacional dos Programas de Pós-Graduação em Administração, 31, Rio de Janeiro, 2007. Anais... Rio de Janeiro: ANPAD, 2007.

GEM (2010). Global Entrepreneurship Monitor. Empreendedorismo no Brasil 2010- Relatório Nacional. IBQP/SEBRAE/IEL.

GETZ, D.; PETERSEN, T. Growth and Prof-oriented entrepreneurship among family business owners in the tourism and hospitality industry: Hospitality Management, v.24, p. 219-242, 2005.

GLANCEY, K; PETTIGREW, M. Entrepreneurship in the small hotel: International Journal of Contemporary Hospitality Management, v. 9, n. 1, p. 21-24, 1997.

HABER, S.; REICHEL, A. The cumulative nature of the entrepreneurial process: The contribution of human capital, planning and environment resources to small venture performance. Journal of Business Venturing, v.22, p. 119-145, 2007.

HONMA, E. T.; TEIXEIRA, R. M. Competências Empreendedoras: Estudo de Casos Múltiplos no Setor Hoteleiro em Curitiba. In: Seminário Internacional de Turismo, 10, Curitiba, 2008. Anais.... Curitiba: Universidade Positivo, 2008.

INSTITUTO PARANAENSE DE DESENVOLVIMENTO ECONÔMICO E SOCIAL- IPARDES. Relatório de Pesquisa, Curitiba, Paraná, 2008.

LERNER, M.; HABER, S. Performance Factors of Small Tourism Ventures: The interfaces of Tourism, Entrepreneurship and the environment. Journal of Business Venturing, v. 16, p 77-100, 2000.

LOCKYER, C.; MORRISON, A. Scottish Tourism Market: Structure, Characteristics and Performance. Report. Scottish Tourism Research Unit/Fraser of Allander Institute, Glasgow: University of Strathclyde, 1999.

LYNCH, P. Female Microentrepreneurs in the lost family sector: Key motivations and social economic Variables, Hospitality Management, v. 17, pp. 319-342, 1998.

MORRISON, A.; RIMMINGTON, M.; WILLIAMS, C. Entrepreneurship in the Hospitality, Butterworth-Heinemann, Oxford, 1999.

MORRISON, A. Entrepreneurs transcend time: a bibliographical analysis. Management Decision, v.39 n; 9, p. 784-790, 2001.

MORRISON, A. Entrepreneurship in Tourism: moving from the generic to the particular, In: Tourism State of the Art II Conference, University of Strathclyde, Glasgow, 2004.

SAUNDERS, M.; LEWIS, P.; THORNILL, A. Research Methods for Business Students. 2. ed. Harlow, England, Pearson Education, 2000. 
SHAW, G.; WILLIAMS, A.M. Entrepreneurship and tourism development, in: IOANNIDES, D. and DEBBAGE, K.G. (eds), The Economic Geography of the Tourist Industry, London, Routledge, p.235-255. 1998.

SZIVAS, E. Entrance into tourism Entrepreneurship: a UK case study: Tourism and Hospitality Research, v.3, n. 2, p. 163-172, 2001.

TEIXEIRA, H. de A. A Trajetória dos Pequenos Negócios do Ramo de Turismo na Região de Belo Horizonte e Poços de Caldas (MG) - um estudo sobre o mito ou a realidade do processo de empreendedorismo: In: Encontro Nacional dos Programas de Pós-Graduação em Administração, ENANPAD, 25, Campinas, SP, 2001. Anais..... ANPAD: Rio De Janeiro, 2001.

TEIXEIRA, R. M.; MORRISON, A. Desenvolvimento de Empresários em Empresas de Pequeno Porte do setor Hoteleiro. Revista de Administração Contemporânea, v. 8 n. 1, jan/mar, p. 105 - 128, 2004.

TEIXEIRA, R. M. Diagnostico de Pequenos Negócios Hoteleiros em Sergipe. In: TRIGO, Luiz Gonzaga Godoi (Ed.). Análises Regionais e Globais do Turismo Brasileiro. São Paulo: Roca, 2005.

TEIXEIRA, R. M. Competências Empreendedoras em Hotéis de Pequeno Porte em Curitiba, Paraná: Análise das Competências Necessárias e Desejadas e Formas de Aprendizagem de Proprietários e Gestores. In Seminário da Associação Nacional Pesquisa e Pós-Graduação em Turismo, 7, São Paulo, 2010. Anais... Universidade Anhembi Morumbi - UAM/ São Paulo, 2010.

YIN, R. K. Estudo de Caso: Planejamento e Métodos. 3. ed. Porto Alegre: Bookman, 2005.

\section{Recebido em: 16/03/2011 (1 ${ }^{\mathrm{a}}$ versão) $15 / 12 / 2011$ ( $2^{\mathrm{a}}$ versão)}

\section{Aprovado em: 15/06/2012}

